\title{
PRINCIPLES OF EFFECTIVE MENTORING COMMUNICATION IN ENTREPRENEURSHIP: THE RESULTS OF A SURVEY OF EXPERTS
}

\author{
Anda Zvaigzne ${ }^{1}$, Dr.oec.; Sandra Murinska², Dr.sc.comm.; Inta Kotane ${ }^{3}$, Mg.oec. \\ Iveta Mietule ${ }^{4}$, Dr.oec. \\ 1,2,3,4 Research Institute for Business and Social Processes, Faculty of Economics and Business Management, \\ Rezekne Academy of Technologies
}

\begin{abstract}
With the development of mentoring networks, communication between mentors and mentees and related problems in entrepreneurship have become an increasingly important topic in recent years. The aim of the research is to identify the most important problems that hinder an effective communication process between the mentor and the mentee in entrepreneurship based on expert opinions on the elements of and barriers to the communication process. The research results have revealed that mentors' willingness to communicate, appropriately engaging in dialogue with their mentees, as well as honour and other skills and traits are essential. The experts have emphasized that it is important that the mentee does not take the mentor's experience literally but critically assesses whether his/her resources are aligned with the goal. According to the experts, the most essential barriers to communication were a lack of time and logical barriers and obstacles that emerged to partners with different ways of thinking. Researchers need to continue the research started by the authors of the paper by working on and designing a communication model for mentors and mentees, taking into account the communication barriers identified in the present research and other factors relevant to communication in entrepreneurship.
\end{abstract}

Key words: mentoring, communication barriers, communication skills, entrepreneurship. JEL code: A00; L26; D83

\section{Introduction}

Anyone communicates with various teachers, influencers and promoters, which indicates that the presence of such a person is important. The role of communication in starting up and developing a business is emphasized in the theoretical literature as well. Those with extensive professional and business contacts are likely to have more information about opportunities, more likely to acquire information at an earlier point, have a larger pool of potential reference providers and 'careerbrokers', and more likely to be known to those who control or affect jobs (Feeney M. K., Bozeman B., 2008). Such a person in business could be a mentor as well. In today's world, a mentor is described as a person with some defined qualities, an expert who oversees and trains a younger person (Memon J., Rozan M. Z. A., et al., 2015). Effective mentoring can contribute to increased selfefficacy and effectiveness and improved and expanded skills and competencies, which can support individual advancement, including in educational and career domains (Montgomery B. L., 2017). When engaged in dyadic mentoring relationship, mentors elaborate and convey supportive messages depicted as "specific lines of communicative behaviour enacted by one party with the intent of benefiting or helping another" (Memon J., Rozan M. Z. A., et al., 2015).

This means that communication and knowledge of principles of effective communication are essential characteristics of mentoring. Mentoring in this top-down framework then emerges as interactions, largely based on a one-way flow of information, between a mentor and an individual being mentored (i.e., a mentee). The focus of the mentoring can include a range of goals, including skills or competency development, psychosocial or socioemotional support, and career development (Montgomery, B. L., 2017).

\footnotetext{
Anda Zvaigzne e-mail: anda.zvaigzne@rta.Iv

2 Sandra Murinska e-mail:sandra.murinska@rta.Iv

3 Inta Kotane e-mail:inta.kotane@rta.Iv

${ }^{4}$ Iveta Mietule e-mail:iveta.mietule@rta.Iv
} 
Mentoring is different from other related forms of discrete support such as teaching and coaching; in case of mentoring, the mentor puts the mentees' interest as complete priority, not as part of a set of priorities. The theoretical literature emphasizes knowledge of the mentor's communication skills and principles to establish effective communication between the mentor and the mentee. Communication opportunities, forms, skills and principles have been analysed and researched in the aspect of business, organizational and interpersonal communication both in Latvia and abroad (Renge V., 2003; Overton R., 2007; Mistre Z., Zvaigzne A., 2012).

The Organisation for Economic Co-operation and Development (OECD) has declared communication as one of the significant $21^{\text {st }}$ century skills (Ester van Laar, et al., 2020). In mentoring, this is the most important tool for achieving results because the mentor alone does not guarantee career growth, yet the quality of the growth depends on the relationship between the mentor and the mentee (LIAA, 2009).

The process of communication between the mentor and the mentee is called interpersonal communication. Interpersonal communication involves interaction between two or more people, usually with a direct connection and with some sort of relationship being assumed. A sufficient understanding of the communication process by the mentor is essential for proper collaboration between the mentor and the mentee.

Mentors need to constantly adjust their communications to meet the needs of their protégés, which demands a "deep understanding of their own communication styles and a willingness to objectively observe the behaviour of the mentee" (Memon J., Rozan M. Z. A., et al., 2015).

An important concept is also organizational communication, especially between the manager and subordinates. There is need for interaction and understanding of management-employee relations hence it will impact on the organizational performances and organizational outcomes. Communication is very essential elements of a successful business. Communication is functions of the management process. When communication is absent in the top-level management to the lower or mid-level management, the organization will not be or is not effective. To implement the management functions of planning, organizing, motivating, leading and controlling, it is very important to maintain the communication among the stakeholders of the organization. Communication is a very important skill and the need for efficient management, through which managers establish and maintain interactions between employees to perform necessary daily tasks properly (Nabi N. M., Foysol K. M., Adnan S. M., 2017). Such communication skills are also described as communication competence. Communication competence is defined as the perceived effectiveness and appropriateness people believe they have as communicators, and it is related with a need to fulfil interpersonal objectives (Velasquez A., Rojas H., 2017).

The concept of communication competence has been uncovered as a key factor for individuals' interpersonal interactions. The notion of communication competence allows for an understanding of the way in which people direct their communication and achieve their relational goals. Communication competence is defined as an individual's disposition for effective and appropriate interaction given a particular interpersonal relational context (Velasquez A., Rojas H., 2017). People perceive the same situation, event or information differently, depending on their individual psychological characteristics, experience and knowledge. Very often, perception problems are determined by the status, position of the communication partner (Renge V., 2003).

Communication competence involves the quality of communication, which is commonly composed of the elements of appropriateness and effectiveness, and communication competencies are believed 
to be among the most central qualifications in the workforce as well (Mikkelson A., York J., Arritola J., 2015).

In terms of significance, social intelligence, empathy, verbal intellectual abilities, self-respect and respect to others, emotional balance, extroverted-introverted dispositions, aggressiveness, flexibility to communicate successfully are equally important. Some research studies have found that the perceived communication competence of a supervisor was related to the employee's satisfaction with the supervisor and a supervisor's communication competence was related to the level of organizational identification in subordinates (Mikkelson A., York J., Arritola J., 2015). The following aspects and stages of building feedback in interpersonal communication are also emphasized (Hartley P., 2001): nonverbal communication, reinforcement, questioning, reflecting, opening and closing, explanation and listening. They provide communication that focuses on mutual understanding and transferring knowledge to the new entrepreneur, which is essential in mentoring $\mathrm{n}$ order to understand whether the mentor has completed his or her mission.

The need for the present research was determined by previous research studies done in the field of mentoring (within the research project Mentoring Opportunities for Entrepreneurship Development in Rezekne Municipality funded from a research grant and implemented by an RTA researcher group in 2018), which have found that that new entrepreneurs need psychological and emotional assistance to start their own businesses, as well as a professional opinion from the other side. To accomplish this, the mentor has to have a high level of communication competence; therefore, the present research sought to identify experts' opinions on key skills in and barriers to communication between the mentor and the mentee (RTA researcher group, 2018).

The research aim is to identify the most important problems that hinder an effective communication process between the mentor and the mentee in entrepreneurship based on expert opinions on the elements of and barriers to the communication process.

To achieve the research aim, the following specific research tasks were set:

1) To theoretically examine the nature of mentoring;

2) To assess the results of a structured survey/interview of experts.

Research methods used: the present research applied the descriptive approach for identifying the behaviours being associated with effective interpersonal communication - defining the skills of interpersonal communication. In addition, the following methods were employed: monographic, analysis, synthesis, statistical analysis and a sociological method - structured expert surveying/interviewing.

The present research conducted a questionnaire survey, in which specialists and experts in communication and business were requested to rate some assertions defined. Statistical analysis methods were employed to process the data.

The present research used specialist literature pertaining to the fields of mentoring and entrepreneurship as well as research papers by foreign and national scientists and other materials as well as articles by industry experts that pertained to the research topic.

\section{Research results and discussion}

There are various uses for mentoring; therefore, there are many different definitions of mentoring. Researcher R. Sullivan emphasizes the strong relationship between the mentor and the mentee that creates a safe environment for the mentee to grow and develop (Sullivan R., 2000). Mentoring could be described as a two-way "communication relationship" consisting of verbal and non-verbal 
behaviour aimed at offering or asking for help. As part of this dialogue communication, the mentor develops and provides supportive messages, described as specific communication behaviours, or actions of one party with the intention of benefiting or helping another (Burleson E., et al., 2002). This means that mentors need to regularly adjust their communication in order to understand each other's needs; therefore, they need an understanding of their communication style, a desire to objectively assess the behaviour of the person being assisted (Radu Lefebvre M., Redien-Collot R., 2013). Mentoring is not an advisor job. It represents a dialogue and an exchange of ideas. The mentor helps the mentee get a broader and more comprehensive view of the business and opportunities for its expansion as well as encourages the mentee to act. The mentor is an experienced, entrepreneurial and knowledgeable entrepreneur or manager or industry specialist who dedicates his or her time, shares the experience and gives advice for free and of his or her own free will to help a new entrepreneur to become competent in the business environment and develop his or her own business, thereby assisting in achieving his or her goals. The mentor listens to the mentee, asks questions, challenges the mentee's goals, examines the mentee, gives advice and shares his or her experience and contacts. The mentee is a prospective or current entrepreneur who wants to start or expand his or her own business with the help of the mentor (LLKC, 2014).

In March 2020, a structured survey/interview of experts in mentoring was conducted by the authors within the project Development and Introduction of a Communication Competencies Model for Enhancing and Maintaining a Business Mentor Network to identify the experts' opinions on barriers to and prerequisites for mentor and mentee communication as well as to find solutions to enhancing the communication. The purpose of the structured survey/interview of experts was to identify the experts' opinions on the communication skills, barriers and problems faced by mentors and mentees in the communication process.

The expert surveying method was adapted to the research hypothesis and the survey was conducted in several successive stages. Initially, based on scientific research studies (Renge V., 2003; Memon J., et al., 2015) and in consultation with experts in mentoring and sociological surveyors, a structured questionnaire was developed by the authors.

The structured questionnaire consisted of three sets of questions, in which the experts rated:

1) the role of rational and emotional aspects and characteristics of mentor communication and of communication skills;

2) the role of non-verbal communication ways;

3) the impact of communication barriers on communication between the mentor and the mentee.

To conduct the survey properly, this specific field was carefully analysed and, in the result, the criteria selected for the survey were subsequently adapted to the objectives of the survey in the form of indicators to be rated in a 5-point system. The experts rated answers to questions by using semantically graduated five-level scales: very unimportant ( 1 point), unimportant ( 2 points), neither important nor unimportant ( 3 points), important (4 points) and very important ( 5 points).

At the next stage, the authors conducted a pilot test of the questionnaire with two industry experts and three researchers. Several inaccuracies were identified in the survey questionnaire concerning the use of terms and an understanding of definitions, which were corrected in a timely manner.

At the third stage, the experts whose professional field, position and experience were relevant to communication problems in mentoring were selected for the survey. The experts were selected based on a prior assessment of their level of competence. Nine experts participated in the structured survey/ interview. The criteria for expert selection were as follows: higher education, at least 10 
years' experience in consulting, managing/ conducting training and entrepreneurship/ communication; the expert had to be socially active and motivated to increase peer engagement in entrepreneurship.

For confidentiality purposes and at the request of the experts, the personal identities of the experts were not disclosed, and the results of the structured survey were presented in an aggregated form. In the expert survey, each expert received a questionnaire that was coded and processed by means of SPSS (Statistical Package for the Social Since) and Microsoft Excel analysis tools.

At the next stage, the data were statistically processed, summarised and interpreted. At the initial stage of the data processing, the authors aggregated the data, computed the mean values, ranked the answers given and grouped and summarized the results.

Rating the role of rational and emotional aspects and characteristics of mentor communication and of communication skills (in a 5-point system), the experts admitted the following factors to be the most important (scored equally): "Skill to actively listen (reflect, ask questions, conclude, discuss)" and "Experience". The experts rated the mentioned factors at 4.89 out of 5 with a mode of 5 that indicated that a rating of 5 was the most frequently given one (Table 1 ).

Table 1

\section{Ratings of the role of rational and emotional aspects and characteristics of mentor communication and of communication skills by the experts, points $(n=9)$}

\begin{tabular}{|c|c|c|}
\hline Factors & $\begin{array}{c}\text { Average } \\
\text { rating }\end{array}$ & Mode \\
\hline Ability to create a wish to communicate and cooperate & 4.78 & 5 \\
\hline Ability to correctly choose the strategy and tactics of dialogue & 4.22 & 5 \\
\hline $\begin{array}{l}\text { Ability to arouse the partner's interest in a topic of conversation and allow the } \\
\text { partner to make an informed choice }\end{array}$ & 4.44 & 4 \\
\hline Ability to ensure correct dialogue & 4.56 & 5 \\
\hline Ability to control one's activity and coordinate it with a communication partner & 4.44 & 4 \\
\hline Ability to regain inner peace after intense communication & 4.00 & $3 a$ \\
\hline Skill to actively listen (reflect, ask questions, conclude, discuss) & 4.89 & 5 \\
\hline $\begin{array}{l}\text { Ability to put oneself in another's shoes, understand each other's emotions and } \\
\text { experiences }\end{array}$ & 4.44 & 5 \\
\hline Ability to interpret a person by appearance and behaviour & 3.44 & 4 \\
\hline Ability to argue & 4.67 & 5 \\
\hline Openness & 4.56 & 5 \\
\hline Honesty & 4.78 & 5 \\
\hline Ability to use modern communication technologies & 4.22 & 4 \\
\hline Ability to communicate electronically & 4,00 & 4 \\
\hline Availability (reachability) & 4.33 & 5 \\
\hline Sex & 3.11 & 4 \\
\hline Age & 3.22 & $3 a$ \\
\hline Nationality & 3.00 & 4 \\
\hline Ideological views & 3.56 & 5 \\
\hline Social status & 3.00 & 3 \\
\hline Education & 3.89 & 4 \\
\hline Experience & 4.89 & 5 \\
\hline
\end{tabular}

a.-There are several modes. The smallest value is presented.

Source: authors' calculations based on the structured survey/interview of experts

The next factors that, according to the experts, were important in mentor communication were as follows: "Ability to create a wish to communicate and cooperate" and "Honesty". The experts rated the mentioned factors on average at 4.78 out of 5 . The choices of the experts were probably affected 
by the idea of respectful communication, which was based on the core values and skills emphasized by a US psychologist, the world-renowned conflict mediator, M. B. Rosenberg in his research studies. M. B. Rosenberg's research has been based on a finding that an individual is, in principle, ready to respect, cooperate and behave calmly as long as the individual trusts that his or her needs are heard and considered as well as respected in action (Rosenberg M. B., 2005).

The experts' opinions on the factors "Ability to regain inner peace after intense communication" and "Age" were different, and it was not possible to identify the most frequently given rating.

Answering the open question of the questionnaire "What skills does an expert need?", four of the nine experts gave diverse answers. The experts gave short answers: "independent" or "the mentor has to be able to inspire peers". Another expert believed that it was "the ability to change the mentee's belief system to synchronize the mentee's goals and available resources so that the mentee does not literally take over the experience but critically assesses the alignment of his or her resources with the goal, and vice versa. The successor has to be given a variety of similar solutions so that the mentee can generate his or her best choice". The third expert believed that "relevant experience and knowledge in the field of the mentored entrepreneur or business (or business expansion that requires support, such as sales promotion, marketing activities etc.) that contributes to an overall entrepreneurship knowledge of the business model and management, as well as a systematic and structured approach to providing targeted and effective mentoring throughout the support phase" are necessary.

Analysing the ratings of the role of non-verbal communication ways given by the experts, it should be noted that the average rating given to 3 out of 6 non-verbal communication ways in the 5-point system was 4 points and above. The experts gave the highest ratings to the following ways of nonverbal communication: a look and eye contact ( 4.78 out of 5 points), voice intonation (4.56 out of 5 points) and facial expressions (4.44 out of 5 points) (Fig. 1). Gestures as a way of non-verbal communication received the lowest expert rating ( 3.56 out of 5 points).

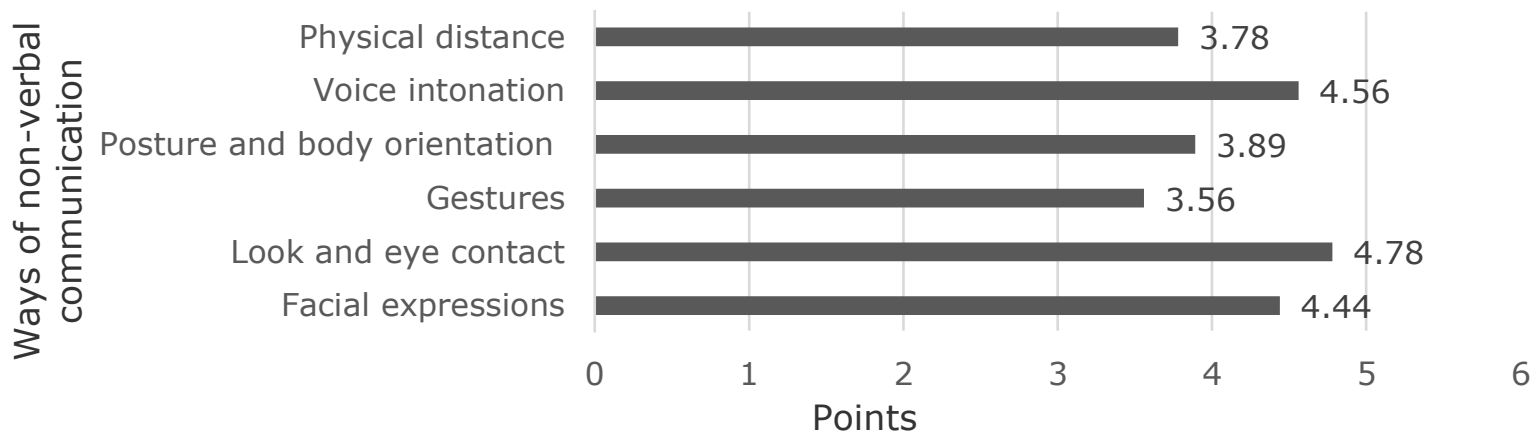

Source: authors' calculations based on the structured survey/interview of experts

Fig. 1 Average ratings of the role of non-verbal communication ways by the experts, points $(\mathbf{n}=9)$

According to the experts, the most essential barriers to communication between the mentor and the mentee were as follows: lack of time ( 4.78 out of 5 points) and logical barriers and obstacles (emerge among partners with different ways of thinking (a rationally minded communication partner is unlikely to accept intuitive arguments)) (4.67 out of 5 points). A mode of the ratings of the mentioned barriers was 5 , which indicated that an expert rating of 5 was the most frequently given one (Table 2). The authors of the research believe that the choice of experts was likely determined by to the fact that an experienced entrepreneur - a potential mentor - invests a lot of time in developing his or her business, has a family and is active in public life; for these reasons, the 
entrepreneur has no time to consult other entrepreneurs. In addition, diverse development levels of individuals lead to different ways of thinking.

\section{Ratings of the impact of communication barriers on communication between the mentor and the mentee by the experts, points $(n=9)$}

\begin{tabular}{|l|c|c|}
\hline \multicolumn{1}{|c|}{ Barriers } & Average rating & Mode \\
\hline 1. Technical barriers and obstacles & 3.22 & $3 a$ \\
\hline 2. Psychological barriers and obstacles & \multicolumn{2}{l|}{} \\
\hline 2.1. Reference system, different status & 3.33 & 4 \\
\hline 2.2. Selective listening & 4.33 & 5 \\
\hline 2.3. Attitude to the communicator & 4.33 & 5 \\
\hline 2.4. Source reliability & 4.56 & 5 \\
\hline 2.5. Filtration & 4.44 & 5 \\
\hline 2.6. Lack of time. & 4.78 & 5 \\
\hline 2.7. Communication overburden & 4.33 & 5 \\
\hline 2.8. Dislike to the form & 4.00 & 4 \\
\hline 3. Psychophysiological barriers & 4.11 & 4 \\
\hline 4. Social barriers and obstacles & 3.89 & 4 \\
\hline 5. Cultural and national barriers and obstacles & 4.00 & 5 \\
\hline 6. Logical barriers and obstacles & 4.67 & 5 \\
\hline 7. Stylistic barriers and obstacles & 4.22 & 5 \\
\hline 8. Semantic barriers and obstacles & 4.11 & 4 \\
\hline 9. Phonemic barriers and obstacles & 3.44 & 3 \\
\hline
\end{tabular}

a.-There are several modes. The smallest value is presented.

Source: authors' calculations based on the structured survey/interviews of experts

Rating the most essential technical barriers and obstacles to communication between the mentor and the mentee, the opinions of the experts differed, which did not allow identifying the most frequently given rating. Technical barriers often relate to environmental factors: communication and Internet problems for remote communication, acoustics, deflecting environmental factors (bright sun, too dark wall colour); weather conditions (too hot or too cold).

\section{Conclusions, proposals, recommendations}

1) Mentoring is one of the most effective ways to transfer successful experience among entrepreneurs by actively sharing knowledge, experience and contacts. Mentoring in entrepreneurship is mainly used to promote the development of new and less experienced enterprises.

2) The research results have revealed that mentors' willingness to communicate, appropriately engaging in dialogue with their mentees, as well as honour and other skills and traits are essential. The experts have emphasized that it is important that the mentee does not take the mentor's experience literally but critically assesses whether his/her resources are aligned with the goal.

3) Feedback is one of the essential components of the communication process; according to the experts, mentoring participants should have skills to actively listen (reflect, ask questions, conclude, follow a thought).

4) The research results have revealed that mentors need relevant experience and knowledge in the field of the mentored entrepreneur or business that contributes to an overall entrepreneurship knowledge of the business model and management, as well as a systematic and structured approach to providing targeted and effective mentoring throughout the support phase. 
5) The research results have revealed that the most essential barriers to communication were a lack of time and logical barriers and obstacles that emerged to partners with different ways of thinking.

6) Researchers need to continue the research started by the authors of the paper by working on and designing a communication model for mentors and mentees, taking into account the communication barriers identified in the present research and other factors relevant to communication in entrepreneurship.

ERASMUS+ project Development and Introduction of a Communication Competencies Model for

Enhancing and Maintaining a Business Mentor Network (DICCMEM.2019-1-LV01-KA203-060414).

\section{Bibliography}

1. Burleson, B., MacGeorge, E., Knapp, M. and Daly, J. (2002). Supportive Communication. Handbook of interpersonal communication ( $3^{\text {rd }}$ ed.). London, England: SAGE, pp. 374-424.

2. Ester van Laar, Alexander, J. A. M. van Deursen, Jan A. G. M. van Dijk, and Jos de Haan (2020). Determinants of 21st-Century Skills and 21st-Century Digital Skills for Workers: A Systematic Literature Review Retrieved:https://www.researchgate.net/publication/338800933_Determinants_of_21stCentury_Skills_and_21stCentury_Digital_Skills_for_Workers_A_Systematic_Literature_Review/link/5e2ae9014585150ee77ee4a4/do wnload Access: 10.03 .2020 .

3. Feeney, M.K., Bozeman, B. (2008). Mentoring and Network Ties. Human Relations, Volume 61, Issue 12, pp.1651-1676.

4. Hartley, P. (2001). Interpersonal Communication ( ${ }^{\text {nd }}$ ed.)London and New York: Routledge, p.42.

5. LIIA (2009). Labas prakses piemeri mentoringa (Examples of Good Practice in Mentoring). Retrieved: www.liaa.gov.Iv/files/liaa/attachments/16_labas_prakses_piemeri_mentoringa.pdf Access: 24.10.2019.

6. LLKC (2014). Biznesa mentoru tikla rokasgramata mentoriem un pieredzes parnemejiem (Business Mentor Network Handbook for Mentors and Mentees). Retrieved: http://new.llkc.lv/sites/default/files/baskik_p/pielikumi/mentorings-vadlinijas.pdf Access: 10.03.2020.

7. Memon, J., Rozan, M. Z. A., Ismail, K., Uddin, M., Daud, D. (2015). Mentoring an Entrepreneur: Guide for a Mentor. SAGE Open, January-March 2015, pp.1-10.

8. Mikkelson, A., York, J., Arritola, J. (2015). Communication Competence, Leadership Behaviors, and Employee Outcomes in Supervisor-Employee Relationships. Business and Professional Communication Quarterly, Volume 78, Issue 3, pp. 336-354.

9. Mistre, Z., Zvaigzne, A. (2012). Assessment of Development Scenarios for The Regional Internal Communication and Information System of the Latvian Blood Donors Service. Proceedings of the 2012 International Conference Economic Science for Rural Development, No.28. Jelgava, LLU ESAF, pp. 91-98.

10. Montgomery, B.L. (2017). Mapping a Mentoring Roadmap and Developing a Supportive Network for Strategic Career Advancement. April-June, pp. 1 -13.

11. Nabi, N.M., Foysol, K.M., Adnan, S.M. (2017). The Role and Impact of Business Communication on Employee Performances and Job Satisfactions: A Case Study on Karmasangsthan Bank Limited, Bangladesh. Arabian Journal of Business and Management Review, Volume 7, Issue 3, pp. 1-8. Retrieved: https://www.hilarispublisher.com/open-access/the-role-and-impact-of-business-communication-onemployee-performancesand-job-satisfactions-a-case-study-on-karmasangsthan-bank-li-2223-58331000301.pdf Access: 10.03.2020.

12. Overton, R. (2007). Business communication. Boat Harbour: Martin Books. p. 97.

13. Radu, Lefebvre, M., Redien-Collot, R. (2013). "How to do things with words": The discursive dimension of experiential learning in entrepreneurial mentoring dyads. Journal of Small Business Management, Volume 51, pp.370-393.

14. Renge, V. (2003). Organizaciju psihologija (Organizational Psychology). Riga: Kamene, pp. 50-57.

15. Rosenberg, M. B. (2003). Nonviolent communication: A language of life ( $2^{\text {nd }}$ ed.). Encinitas: Puddle Dancer Press, p.240.

16. RTA researcher group (2018). Research project: Mentoring Opportunities for Entrepreneurship Development in Rezekne Municipality: Rezekne Academy of Technologies, p. 47.

17. Sullivan, R. (2000). Entrepreneurial learning and mentoring. International Journal of Entrepreneurial Behaviour and Research, Volume 6, Issue 3, pp.160-175.

18. Velasquez, A., Rojas, H. (2017). Political Expression on Social Media: The Role of Communication Competence and Expected Outcomes. Social Media + Society, January - March, pp.1 -13. 